\title{
Ring opening of monocyclic dimethyl cyclopropene via metathesis by tungsten catalyst- A computational study
}

\author{
JAY SINGH MEENA and POMPOZHI PROTASIS THANKACHAN* \\ Department of Chemistry, Indian Institute of Technology Roorkee, Roorkee 247 667, India \\ e-mail: pthankachan1950@gmail.com;jaymeena.jay@gmail.com
}

MS received 17 October 2013; revised 15 January 2014; accepted 20 January 2014

\begin{abstract}
Metathesis reaction of 3,3-disubstituted cyclopropene mediated by the model catalyst tungsten alkylidene $\mathrm{W}(\mathrm{NH})\left(\mathrm{CH}_{2}\right)\left(\mathrm{OCH}_{3}\right)_{2}$ has been studied at the B3LYP/LANL2DZ level of theory. The stationary points on the potential energy surface for ring opening metathesis were calculated considering all stereochemically distinct approaches of the 3,3-disubstituted cyclopropene to the model tungsten catalyst. The ring opening of cyclopropene moiety proceeds in two steps i.e., cycloaddition and ring opening. Each step involves a twisted trigonal bipyramidal transition structure. The syn orientation of cyclopropene to the $\mathrm{NH}$ group of the tungsten alkylidene is more favourable for product formation. Cyclopropene addition to tungsten alkylidene takes place preferentially on the CNO face; which is favoured by $10.89 \mathrm{kcal} / \mathrm{mol}$ over the COO face. The energy barriers for the syn cycloaddition and syn ring opening steps are 8.47 and $10.94 \mathrm{kcal} / \mathrm{mol}$, respectively. The ring opening step is the rate determining step for the reaction of cyclopropene with tungsten catalyst, in contrast with the case of the molybdenum catalyst.
\end{abstract}

Keywords. Cyclopropene; olefin metathesis; monocyclic; DFT; ring opening.

\section{Introduction}

Olefin metathesis represents a unique class of new $\mathrm{C}-\mathrm{C}$ double bond forming transformations that has considerable potential in organic chemistry. ${ }^{1-5}$ The welldefined transition metal based alkylidene and carbene complexes introduced by Schrock et al. ${ }^{6,7}$ and Grubbs et al. ${ }^{8}$ catalyse this group of reactions. The catalytic ring opening metathesis (ROM) generates a new metalalkylidene complex that can take part in a subsequent metathesis step in living ring opening metathesis polymerization (ROMP), ${ }^{9}, 10$ and tandem ring openingcross metathesis (ROCM) ${ }^{11}$ or ring opening-ring closing metathesis (RO-RCM). ${ }^{12}$ Cyclic olefins react irreversibly with a metal alkylidene to give a new ring opened alkylidene as a product.

The ring opening metathesis proceeds through the well-accepted Chauvin mechanism, ${ }^{13}$ which involves a metallacyclobutane (MCB) as an intermediate. The mechanistic scheme of ring opening metathesis reaction, based on Chauvin mechanism, is shown in scheme 1. This process is thermodynamically controlled and the requisite driving force of the reaction is the release of strain associated with the cyclic olefins.

*For correspondence
Various cyclic olefins undergo ring opening metathesis polymerization to give a range of macromolecules. Norbornene, Norbornadiene,7-Oxanorbornadiene and their derivatives are cyclic monomers that have been used previously. ${ }^{10,14,15}$

The ring opening metathesis polymerization of monocyclic olefins is more difficult than normal olefin metathesis as the strained rings cannot be reformed by ring closing metathesis (RCM). ${ }^{16}$ Cyclopropenes ${ }^{17}$ and cyclobutenes ${ }^{18}$ are the only monocyclic olefins that have been polymerized successfully in living fashion by means of ring opening metathesis polymerization. However, lack of monocyclic substrates appropriate for 'living' ROMP has limited the scope of this field. ${ }^{19}$ 3,3-Disubstituted cyclopropene derivatives appear to be interesting monocyclic olefins for the polymerization because of their ready availability and highly strained ring structure (cyclopropene ring strain energy is $\approx 55 \mathrm{kcal} / \mathrm{mol}) .{ }^{20}$ The first report of cyclopropene polymerization in a living manner via ROMP was made by Schrock et al. in 2006. ${ }^{21}$ In recent years several experimental reports on ROMP of 3,3-disubstituted cyclopropenes with molybdenum alkylidene complexes of the type $\mathrm{Mo}(\mathrm{NAr})\left(\mathrm{CHR}^{\prime}\right)(\mathrm{OR})_{2}$ and ruthenium catalysts have been published. ${ }^{17,22}$

Presently, computational modelling is routinely used as a potential tool in the elucidation of the reaction 


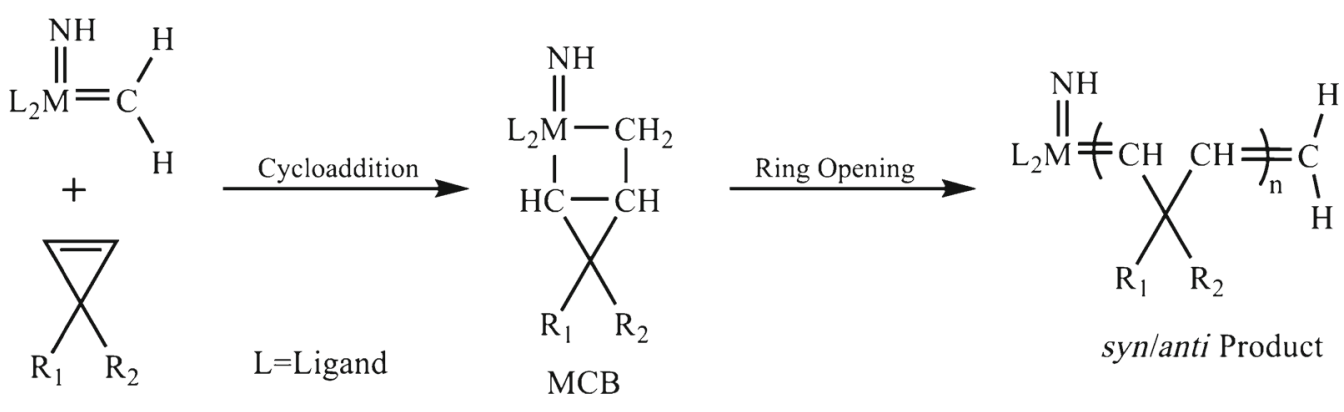

Scheme 1. Mechanism of ring opening of 3,3-disubstituted cyclopropene via metathesis.

mechanism ${ }^{23-25}$ and in the prediction of the reactivity of many challenging olefins. ${ }^{26,27}$ Various theoretical aspects of reactions involving cyclic olefins have been studied. ${ }^{28-30}$ However, no attention has been paid to the peculiarities of the ring opening metathesis of the highly strained monocyclic cyclopropene moiety. Recently a computational study of the molybdenum catalysed ROMP has been reported from our laboratory, ${ }^{31}$ but to the best of our knowledge, theoretical studies of ROM of cyclopropene with tungsten alkylidene have not been reported to date. The objective of the present study is to model ring opening of cyclopropene via metathesis with Schrock's tungsten catalyst model. Systematic computational studies of the ring opening metathesis are performed on 3,3-dimethyl cyclopropene (DMCP) with the realistic model catalyst $\mathrm{W}(\mathrm{NH})\left(\mathrm{CH}_{2}\right)\left(\mathrm{OCH}_{3}\right)_{2}$. The current study is aimed at a description of the mechanistic details on the ring opening of 3,3-dimethyl cyclopropene via metathesis mechanism.

\section{Computational details}

The geometries of all stationary structures involved including stable species, intermediates and transition state were optimized using the hybrid B3LYP functional as implemented in Gaussian 09 (revision A.02). ${ }^{32}$ The B3LYP functional is a combination of Becke's three-parameter hybrid exchange functional ${ }^{33}$ with the Lee-Yang-Parr non-local correlation functional. ${ }^{34}$ As relativistic effects are significant in the case of tungsten the LANL2DZ basis set was used, which includes HayWadt effective core potential (ECP) $)^{35}$ plus double-zeta basis set for tungsten and Dunning-Huzinaga valence double-zeta set (D95V) for the first row atoms C, $\mathrm{O}$ and for hydrogen. Previous work ${ }^{31,36-38}$ has shown that B3LYP/LANL2DZ is a reasonable combination to study olefin metathesis reactions catalysed by tungsten and molybdenum based alkylidene complexes. The ultrafine grid, which is a pruned $(99,590)$ grid, was used during the computations. Harmonic vibrational frequencies were calculated for each optimized structure to ensure that the stationary points identified on the potential energy surface correspond to either a minimum (zero imaginary frequencies) or a transition state (one imaginary frequency). The transition structures were additionally verified by intrinsic reaction coordinate (IRC) calculations. ${ }^{39,40}$

\section{Results and discussion}

The reaction of cyclopropene (2) with tungsten alkylidene model $\mathrm{W}(\mathrm{NH})\left(\mathrm{CH}_{2}\right)\left(\mathrm{OCH}_{3}\right)_{2}$ (1) may occur on two likely faces $(\mathrm{COO} / \mathrm{CNO})$ of the catalyst as shown in figure 1. On the $\mathrm{CNO}$ face, cyclopropene may approach in syn or anti orientation as shown in figure 2. In syn approach, the substituted carbon of the cyclopropene is directed upward to the $\mathrm{NH}$ group of the catalyst and downward in anti approach. The computed total electronic energies, enthalpies (at $298 \mathrm{~K}$ ), and free energies of the reactants, transition structures, intermediates and products involved in reaction are given in table 1. The important geometrical parameters of the optimized structures are given in table 2. A more extensive list of geometrical parameters of these structures is provided in table $\mathrm{S} 1$ and table $\mathrm{S} 2$ of supplementary information.
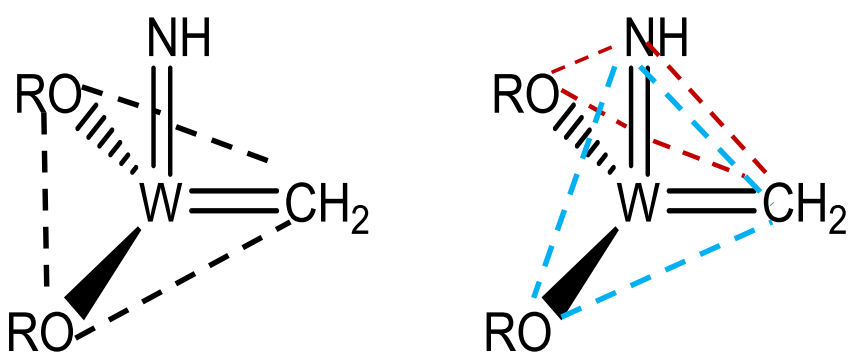

Figure 1. $\mathrm{COO}$ and $\mathrm{CNO}$ faces of the $\mathrm{W}(\mathrm{NH})\left(\mathrm{CH}_{2}\right)$ $\left(\mathrm{OCH}_{3}\right)_{2}$ catalyst. 


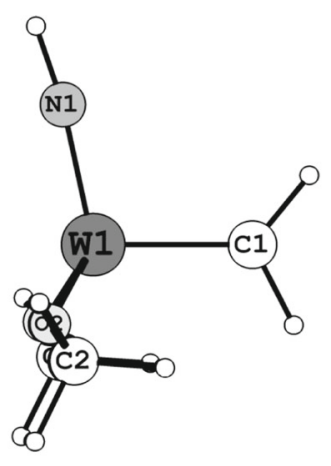

1

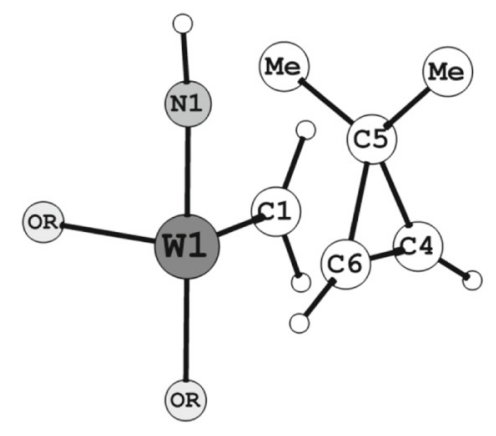

syn

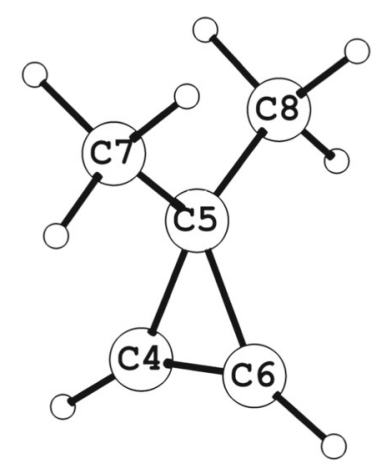

2

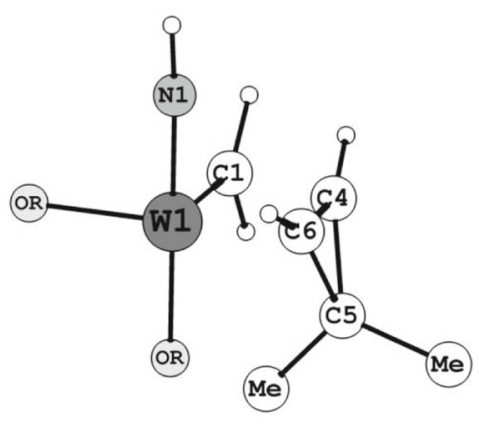

anti

Figure 2. syn and anti orientations of 3,3-dimethyl cyclopropene (2) at the CNO face of the model tungsten catalyst $\mathrm{W}(\mathrm{NH})\left(\mathrm{CH}_{2}\right)\left(\mathrm{OCH}_{3}\right)_{2}(\mathbf{1})$.

\subsection{Cycloaddition step}

3.1a Transition structure on CNO face: The structures of the model catalyst (1) and of 3,3-dimethyl cyclopropene (2) along with their syn and anti relative orientations on the CNO face are shown in figure 2. Each orientation leads to a pseudo-trigonal bipyramidal transition structure with the $\mathrm{NH}$ and one of the alkoxy (OR) groups occupying the axial positions, and a four centred ring is formed in the equatorial plane, as in the structures of the TBP tungstacyclobutane intermediates determined by X-ray crystal structure analysis. ${ }^{41}$ In figure 3, SCTS and ACTS represent the optimized geometry of the syn and anti trigonal bipyramidal

Table 1. Calculated relative energies $\left(\Delta \mathrm{E}_{\mathrm{e}}\right.$, in kcal mol$\left.{ }^{-1}\right)$, enthalpies $\left(\Delta \mathrm{H}_{298}\right.$, in kcal mol $\left.{ }^{-1}\right)$ and free energies $\left(\Delta \mathrm{G}_{298}\right.$, in $\mathrm{kcal} \mathrm{mol}^{-1}$ ) for the transition structures (TS), trigonal bipyramidal (TBP), square pyramidal (SP) and ring opening metathesis product of 3,3-dimethyl cyclopropene with $\mathrm{W}(\mathrm{NH})\left(\mathrm{CH}_{2}\right)\left(\mathrm{OCH}_{3}\right)_{2}$.

\begin{tabular}{|c|c|c|c|c|c|c|c|}
\hline \multirow[b]{2}{*}{ Sl. no } & \multirow[b]{2}{*}{ Structure } & \multicolumn{3}{|c|}{ Syn } & \multicolumn{3}{|c|}{ Anti } \\
\hline & & $\Delta \mathrm{E}_{\mathrm{e}}$ & $\Delta \mathrm{H}$ & $\Delta \mathrm{G}$ & $\Delta \mathrm{E}_{\mathrm{e}}$ & $\Delta \mathrm{H}$ & $\Delta \mathrm{G}$ \\
\hline \multicolumn{8}{|c|}{ CNO Face } \\
\hline 1. & Reactants & 0 & 0 & 0 & 0 & 0 & 0 \\
\hline 2. & Cycloaddition TS & 8.47 & 9.17 & 23.03 & 10.28 & 11.0 & 25.22 \\
\hline 3. & TBP intermediate & -37.77 & -33.76 & -17.91 & -36.41 & -32.41 & -15.97 \\
\hline 4. & SP intermediate & -41.71 & -37.97 & -23.55 & -42.25 & -38.59 & -23.78 \\
\hline \multirow{2}{*}{5.} & Ring opening TS & -30.77 & -28.09 & -12.07 & -29.24 & -26.32 & -9.61 \\
\hline & Ring opening $\mathrm{TS}^{\mathrm{a}}$ & 10.94 & 9.88 & 11.48 & 13.01 & 12.26 & 14.17 \\
\hline 6. & Product & -55.52 & -52.02 & -39.53 & -54.55 & -50.72 & -38.14 \\
\hline \multicolumn{8}{|c|}{ COO Face } \\
\hline 7. & Cycloaddition TS & 19.36 & 19.82 & 34.72 & & & \\
\hline 8. & TBP intermediate & -26.22 & -22.55 & -5.95 & & & \\
\hline
\end{tabular}

${ }^{\text {a}}$ Energy relative to the most stable syn and anti SP intermediate 
Table 2. Optimized structural parameters (bond lengths in $\AA$ and angles in degree) for the transition structures (TS), trigonal bipyramidal (TBP), square pyramidal (SP) and ring opening metathesis product (LM) of 3,3-dimethyl cyclopropene with $\mathrm{W}(\mathrm{NH})\left(\mathrm{CH}_{2}\right)\left(\mathrm{OCH}_{3}\right)_{2}$.

\begin{tabular}{|c|c|c|c|c|c|c|c|c|c|c|c|}
\hline \multirow[b]{3}{*}{ Sl. no. } & \multirow[b]{3}{*}{ Parameter } & \multicolumn{10}{|c|}{$\mathrm{W}(\mathrm{NH})\left(\mathrm{CH}_{2}\right)\left(\mathrm{OCH}_{3}\right)_{2}+3,3 \mathrm{DMCP}$} \\
\hline & & \multicolumn{5}{|c|}{ Syn } & \multicolumn{5}{|c|}{ Anti } \\
\hline & & SCTS & STBP & SSP & SRTS & SROP & ACTS & ATBP & ASP & ARTS & AROP \\
\hline 1. & W1-N1 & 1.769 & 1.778 & 1.747 & 1.771 & 1.753 & 1.771 & 1.778 & 1.749 & 1.767 & 1.751 \\
\hline 2. & W1-C1 & 1.922 & 2.170 & 2.207 & 2.686 & - & 1.927 & 2.180 & 2.211 & 2.814 & - \\
\hline 3. & W1-C6 & 2.864 & 2.048 & 2.144 & 1.958 & 1.912 & 2.697 & 2.042 & 2.152 & 1.956 & 1.927 \\
\hline 4. & $\mathrm{C} 1-\mathrm{C} 4$ & 3.184 & 1.520 & 1.523 & 1.387 & 1.349 & 2.998 & 1.514 & 1.524 & 1.378 & 1.350 \\
\hline 5. & C4-C6 & 1.336 & 1.677 & 1.579 & 2.155 & - & 1.345 & 1.692 & 1.551 & 2.179 & - \\
\hline 6. & N1-W1-O2 & 140.0 & 169.9 & 112.1 & 134.8 & 115.2 & 154.3 & 163.2 & 113.6 & 133.8 & 115.3 \\
\hline 7. & C1-W1-O1 & 103.1 & 143.3 & 138.5 & 170.2 & - & 104.6 & 147.5 & 140.4 & 154.7 & - \\
\hline 8. & $\mathrm{C} 1-\mathrm{W} 1-\mathrm{O} 2$ & 113.0 & 88.0 & 85.0 & 83.9 & - & 110.1 & 82.4 & 86.1 & 71.0 & - \\
\hline 9. & C6-W1-O1 & 152.5 & 134.6 & 84.8 & 106.8 & 106.9 & 151.6 & 129.5 & 86.2 & 107.7 & 108.6 \\
\hline 10. & C6-W-O2 & 74.0 & 90.6 & 137.7 & 113.8 & 106.4 & 77.0 & 98.8 & 139.2 & 118.7 & 107.7 \\
\hline 11. & C1-W1-C6 & 102.9 & 80.1 & 66.4 & 80.2 & - & 102.2 & 79.9 & 65.6 & 77.4 & - \\
\hline 12. & W-C1-C4 & 64.5 & 80.4 & 95.5 & 76.1 & - & 66.3 & 80.8 & 96.1 & 77.2 & - \\
\hline 13. & $\mathrm{C} 1-\mathrm{C} 4-\mathrm{C} 6$ & 106.6 & 116.2 & 100.4 & 116.8 & - & 107.2 & 115.6 & 100.5 & 116.8 & - \\
\hline 14. & W1-C6-C4 & 79.3 & 80.9 & 96.3 & 82.3 & - & 81.9 & 81.3 & 97.7 & 86.8 & - \\
\hline
\end{tabular}

transition structures of the cycloaddition step respectively. The selected geometrical parameters of these structures are given in table 2.

In both syn and anti transition structures, the alkylidene bonds (W1-C1) have been slightly elongated while a new bond (W1-C6) is seen forming between tungsten and cyclopropene carbon. The newly forming (W1-C6) bonds are about $2.86 \AA$ and $2.70 \AA$ in length in SCTS and ACTS, respectively (entry 3 in table 2). The shorter bond length in ACTS suggests a slightly earlier transition state for the anti addition. The angle $\mathrm{C} 1-\mathrm{W} 1-\mathrm{O} 1$ is about $103-105^{\circ}$ and the C6-W1-O1 angle is nearly $152^{\circ}$. The alkylidene carbon centres are essentially planar, while there are large distortions from planarity in the reacting C4-C6 double bond carbon centres. This is due to the steric repulsion of the C5 centre of the cyclopropene with the $\mathrm{NH}$ group in syn transition structure and the axial alkoxy $\left(-\mathrm{OCH}_{3}\right)$ group in anti transition structures.

The computed activation enthalpy for syn addition of cyclopropene with $\mathrm{W}(\mathrm{NH})\left(\mathrm{CH}_{2}\right)\left(\mathrm{OCH}_{3}\right)_{2}$ is $9.2 \mathrm{kcal} / \mathrm{mol}$ and about $11.0 \mathrm{kcal} / \mathrm{mol}$ for anti addition (see entry 2 in table 1 ). The experimental activation enthalpy for the formation of metallacyclobutane intermediate from norbornadiene is reported to be about $6.6 \mathrm{kcal} / \mathrm{mol}$ for the reaction of $\mathrm{W}(\mathrm{NAr})(\mathrm{CH}-\mathrm{t}-$ $\mathrm{Bu})(\mathrm{O}-\mathrm{t}-\mathrm{Bu})_{2}$ with 2,3-bis(trifluoromethyl) norbornadiene (NBDF6). ${ }^{42}$ The increased activation enthalpy for cyclopropene is presumably due to the high ring strain of cyclopropene. The transition structure for syn addition (SCTS) is more stable than that for anti addition (ACTS) by about $1.83 \mathrm{kcal} / \mathrm{mol}$. The pervious
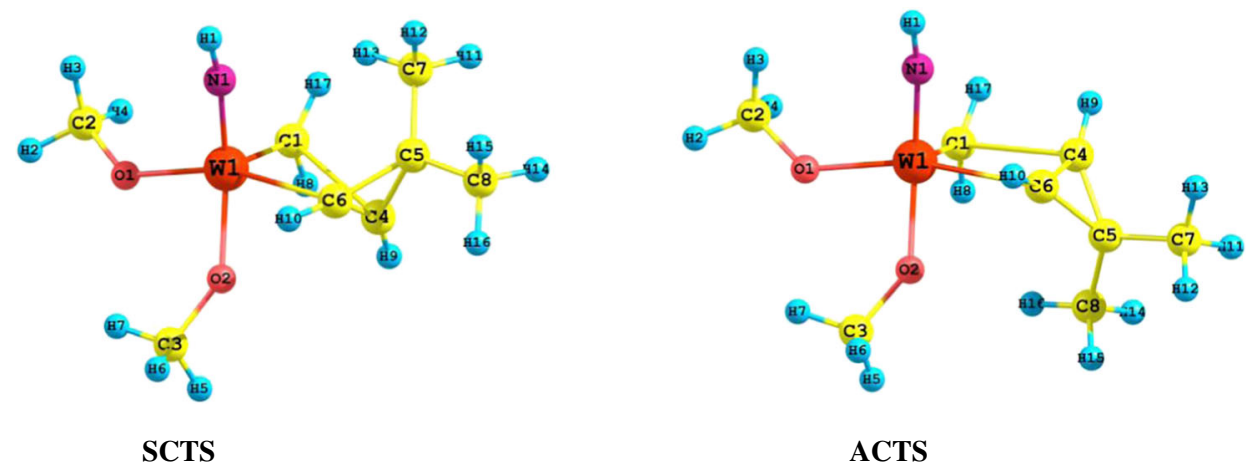

Figure 3. Optimized transition state structures of 3,3-dimethyl cyclopropene reaction on the $\mathrm{CNO}$ face of $\mathrm{W}(\mathrm{NH})\left(\mathrm{CH}_{2}\right)\left(\mathrm{OCH}_{3}\right)_{2}$ catalyst. 
experimental $^{43}$ and theoretical studies of cyclic olefins with molybdenum alkylidene have also shown preference for syn addition over anti addition. ${ }^{30,31}$

3.1b Transition structure on COO face: Figure 4 shows the transition structure and trigonal bipyramidal intermediate for the addition of cyclopropene to the $\mathrm{COO}$ face of $\mathrm{W}(\mathrm{NH})\left(\mathrm{CH}_{2}\right)\left(\mathrm{OCH}_{3}\right)_{2}$ catalyst. The trigonal bipyramidal transition structure and intermediate found in this case are denoted as COO_TS and COO_TBP, respectively. COO_TS also has a distorted trigonal bipyramidal geometry but two alkoxy $\left(-\mathrm{OCH}_{3}\right)$ groups occupy axial positions and the $\mathrm{NH}$ group occupies an equatorial position which is different from the structures SCTS and ACTS of the CNO face.

The calculated activation enthalpies for cyclopropene addition on the COO face is about $19.82 \mathrm{kcal} / \mathrm{mol}$, see table 1 , entry 7 . The activation enthalpy barrier for the reaction at $\mathrm{CNO}$ face is lower than at the $\mathrm{COO}$ face about 10.89 and $9.08 \mathrm{kcal} / \mathrm{mol}$ (see entry 2 for syn/anti $\mathrm{CNO}$ and 7 for $\mathrm{COO}$ in table 1). The free energy values (see table 1) also support this CNO face preference. In the $\mathrm{COO}$ face transition structure (COO_TS), steric repulsion between one of the axial methoxy group $\left(-\mathrm{OCH}_{3}\right)$ and methyl groups of cyclopropene is larger whereas this steric repulsion is smaller between $\mathrm{NH}$ group and methyl groups of cyclopropene in transition structure (SCTS and ACTS) at CNO face. The larger steric repulsion increases the destabilization of structure at $\mathrm{COO}$ face. Therefore, we conclude that ring opening of 3,3-dimethyl cyclopropene takes place preferentially on the CNO face. Consequently, in subsequent stages we restrict our studies to reaction at the $\mathrm{CNO}$ face alone. 3.1c TBP and SP Metallacyclobutane intermediates: Syn and anti tungstacyclobutane intermediates with trigonal bipyramidal (TBP) geometry are formed via corresponding transition states SCTS and ACTS. These intermediates are represented as STBP and ATBP and by a Berry type pseudorotation can convert to square pyramidal (SP) intermediate SSP and ASP, respectively, as shown in figure 5. The trigonal bipyramidal tungstacyclobutane intermediate (COO_TBP) of the COO face is also shown in figure 4 and geometry is not further discussed because of the unfavourable energetics. However, geometrical details of COO_TBP are given in table S3 of supporting information. Further discussion in this section concentrates on the CNO face alone.

The geometries of each structure are similar to the previously obtained X-ray crystal structures of similar compounds ${ }^{41}$ and theoretically computed structures of cyclic olefins reaction with molybdenum model catalyst. $^{30,31}$ The trigonal bipyramidal intermediates can also possibly rearrange by a Berry-type pseudorotation to the square pyramidal geometry. ${ }^{43,44}$ However, we were unable to characterize the corresponding transition structures. In the TBP structures, the C4C6 bonds of metallacyclobutane ring (W1-C1-C4-C6) are unusually long, about $1.68-1.69 \AA$ while the other C1-C4 bonds are normal (1.52 $\AA$ ). The newly forming bonds (W1-C6) are about $2.1 \AA$ which is significantly shorter than observed in transition structures. On the other hand, metal-carbene carbon bond (W1-C1) has elongated (2.2 $\AA$ ). In square pyramidal tungstacyclobutane ring the $\mathrm{C} 4-\mathrm{C} 6$ and $\mathrm{C} 1-\mathrm{C} 4$ both bonds are shorter (in the range of $1.52-1.58 \AA$ ) as compared to TBP intermediates, which is in similar trend to the previous theoretical studies. ${ }^{45}$ In general, the calculated
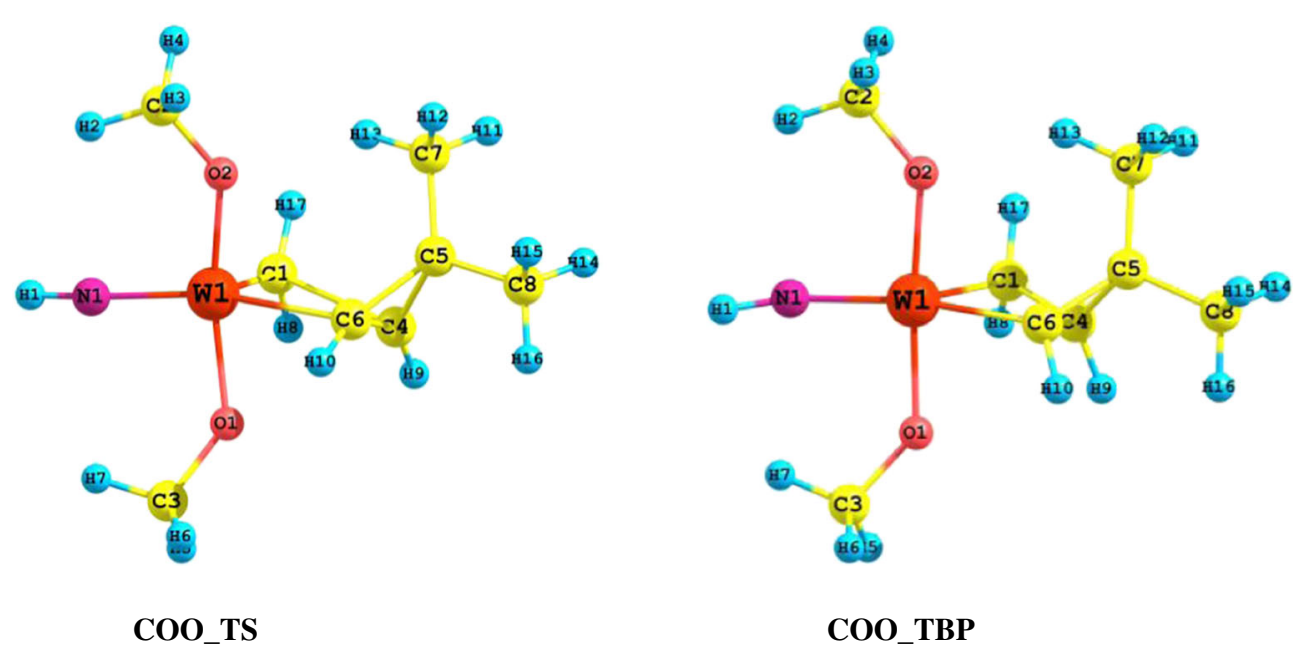

Figure 4. Optimized transition structure and trigonal bipyramidal intermediates of cyclopropene reaction on the $\mathrm{COO}$ Face of $\mathrm{W}(\mathrm{NH})\left(\mathrm{CH}_{2}\right)\left(\mathrm{OCH}_{3}\right)_{2}$ catalyst. 


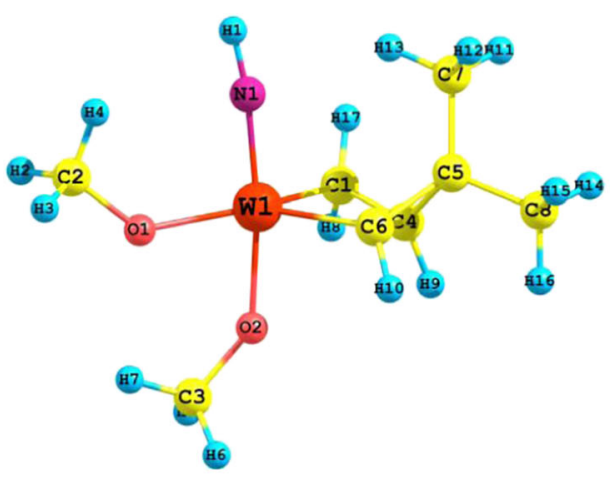

STBP

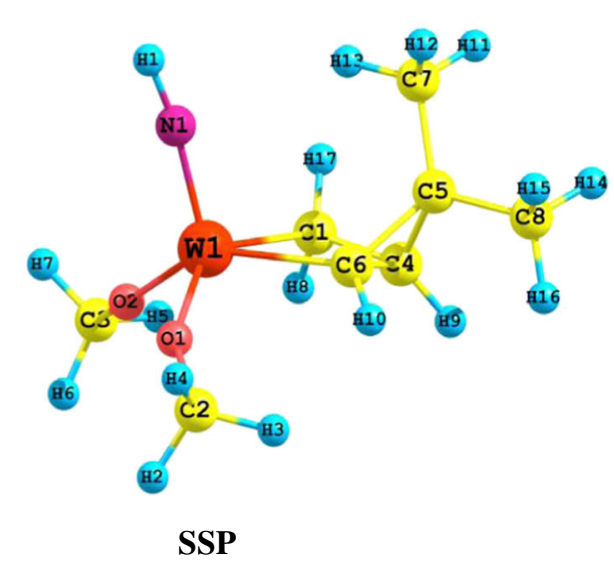

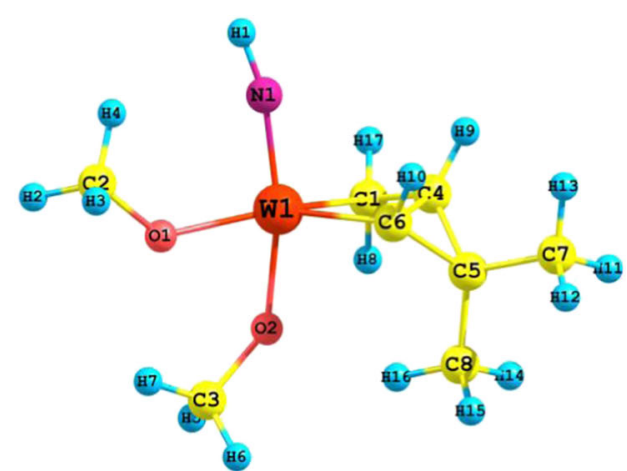

ATBP

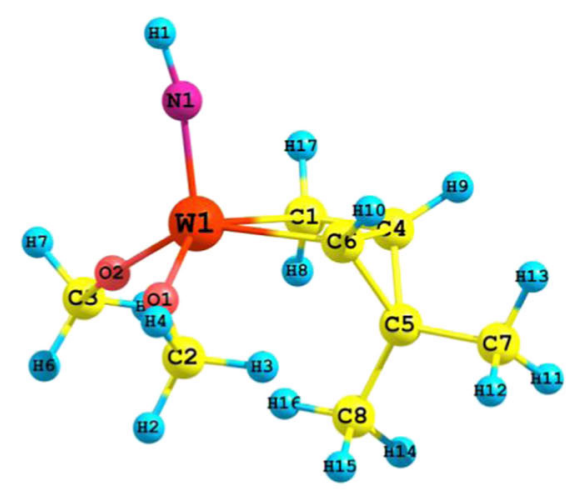

ASP

Figure 5. Optimized structures of trigonal bipyramidal and square pyramidal intermediates of cyclopropene reaction on the $\mathrm{CNO}$ face of $\mathrm{W}(\mathrm{NH})\left(\mathrm{CH}_{2}\right)\left(\mathrm{OCH}_{3}\right)_{2}$ catalyst.

bond lengths are somewhat longer than those found for X-ray structures. The geometrical requirement in the core tungstacyclobutane part of the TBP structures causes significant strain in the cyclopropene ring (C4-C5-C6), thus making the C4-C6 bonds much longer. These very long bonds in STBP and ATBP indicate that they are unstable. The difference between the TBP and SP intermediates is due to the different core rings present, ${ }^{41}$ the $\mathrm{W} 1-\mathrm{C} 1-\mathrm{C} 4, \mathrm{~W} 1-\mathrm{C} 6-\mathrm{C} 4$ and $\mathrm{C} 1-\mathrm{W} 1-\mathrm{C} 6$ are about $79-80^{\circ}$ and $\mathrm{C} 1-\mathrm{C} 4-\mathrm{C} 6$ are about $116^{\circ}$ while in the SP intermediates, the $\mathrm{W} 1-\mathrm{C} 6-\mathrm{C} 4$, $\mathrm{C} 1-\mathrm{W} 1-\mathrm{C} 6$ and $\mathrm{C} 1-\mathrm{C} 4-\mathrm{C} 6$ are about $79-80^{\circ}$ and $\mathrm{C} 1-\mathrm{W} 1-\mathrm{C} 6$ angles are about $66^{\circ}$ (see entries $11-14$ in table 2).

The calculated enthalpies for the tungstacyclobutanes of the reaction show that the syn and anti square pyramidal intermediates (SSP and ASP) are more stable than the corresponding syn and anti trigonal bipyramidal (STBP and ATBP) intermediates. The SSP and ASP intermediates are calculated to be more stable by 4.21 and $6.18 \mathrm{kcal} / \mathrm{mol}$, respectively than the STBP and ATBP intermediates. STBP is more stable than ATBP by $1.35 \mathrm{kcal} / \mathrm{mol}$, while ASP is about $0.62 \mathrm{kcal} / \mathrm{mol}$ more stable than SSP intermediate. Smaller energy difference $(4.21 \mathrm{kcal} / \mathrm{mol})$ between STBP and SSP intermediates suggests that syn oriented TBP can rearrange to syn square pyramidal form easier than the anti orientation.

\subsection{Ring opening step}

3.2a Transition structures: As in the case of the cycloaddition step, the transition states (TS) for ring opening step are also in trigonal bipyramidal geometry with the $\mathrm{NH}$ group and one of the alkoxy $\left(-\mathrm{OCH}_{3}\right)$ groups occupying the axial positions but are much more twisted. We were unable to find transition structure that connects the SP intermediates and products, and it seems that SP tungstacyclobutane cannot decompose directly to the tungsten alkylidene $(\mathrm{W}=\mathrm{C})$ centre and olefin, while avoiding the TBP intermediate. ${ }^{46}$ The ring opening transition structures corresponding to syn and anti tungstacyclobutanes are shown in figure 6 and denoted as SRTS and ARTS, respectively. 


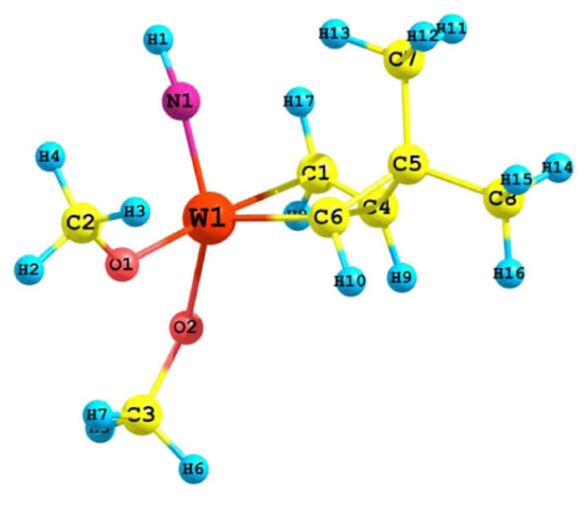

SRTS

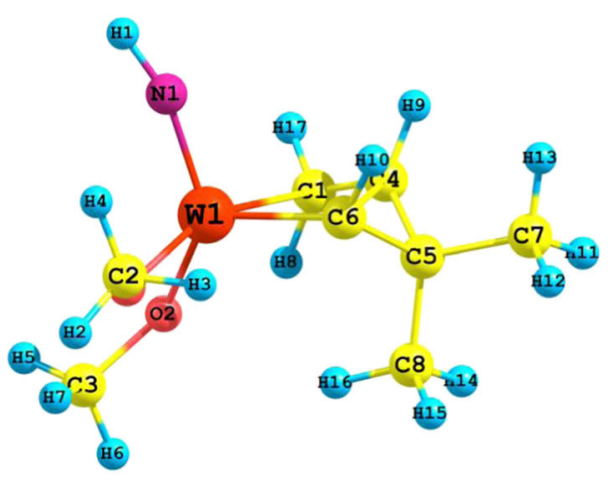

ARTS

Figure 6. Optimized syn and anti transition structures of the ring opening step.

In ring opening transition structures, the $\mathrm{C} 1-\mathrm{W} 1-\mathrm{O} 1$ angles are increased to $170^{\circ}$ in SRTS and $155^{\circ}$ in ARTS, on the other hand, C6-W1-O1 angles have decreased in comparison to cycloaddition transition structures (see entry 9, table 2). On comparison with TBP intermediates, the breaking $\mathrm{W} 1-\mathrm{C} 1$ and $\mathrm{C} 4-\mathrm{C} 6$ bonds have been lengthened by about 0.52 and $0.48 \AA$ in SRTS and 0.73 and $0.49 \AA$ in ARTS, while forming $\mathrm{C} 1=\mathrm{C} 4$ bonds are shorter by $0.13 \AA$ and the $\mathrm{W} 1=\mathrm{C} 6$ bond is also significantly shorter (see entry 3 , table 2 ) in both structures. Consequently, the calculated ring opening transition structures reflect the earlier prediction that the C4-C6 bonds in the TBP intermediates can be easily broken. This is also reflected in the computed energies, the SRTS and ARTS barriers are higher in energy than their analogous STBP and ATBP by about $7 \mathrm{kcal} / \mathrm{mol}$, while relative to the corresponding SP intermediates the calculated activation barriers are notably higher at about 10.94 and $13.01 \mathrm{kcal} / \mathrm{mol}$, respectively (see entry 5, table 1). The activation enthalpy for syn ring opening is lower by $2.38 \mathrm{kcal} / \mathrm{mol}$ than anti ring opening. The ring opening barriers are much higher than those found for the cycloaddition step leading us to predict that the ring opening step is the rate determining step of the ring opening via metathesis of 3,3-dimethyl cyclopropene with tungsten catalyst. This is in contrast with the case of the molybdenum catalyst. ${ }^{31}$ but in agreement with the general trend found by experiments that tungstacyclobutane intermediates appear to break up more slower than their molybdenum counterparts. ${ }^{47}$ The ring opening activation enthalpies for similar reaction of cyclopropene with $\mathrm{Mo}(\mathrm{NH})\left(\mathrm{CH}_{2}\right)\left(\mathrm{OCH}_{3}\right)_{2}$ are only 5.03 and $4.68 \mathrm{kcal} / \mathrm{mol}$ for syn and anti paths, respectively. ${ }^{31}$ The lower activation energy, of cycloaddition and ring

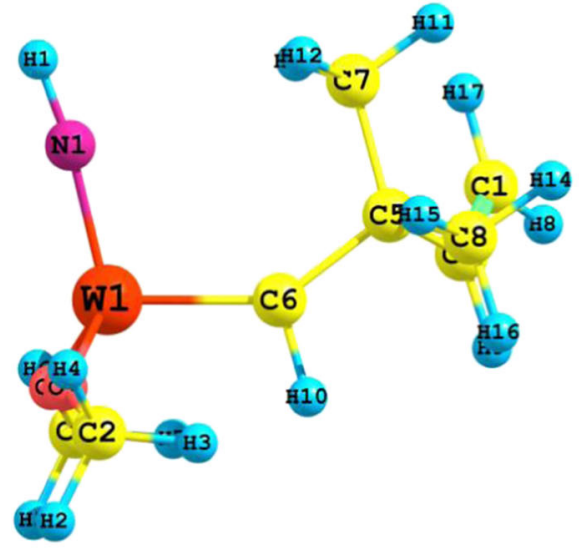

SROP

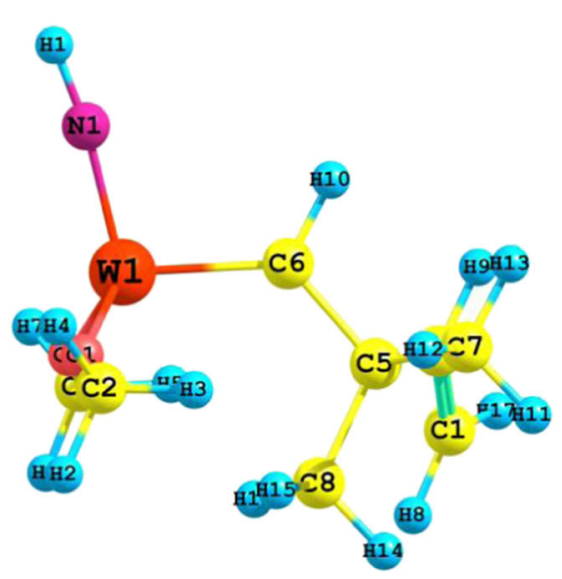

AROP

Figure 7. Optimized syn and anti ring opening products of the cyclopropene reaction on the $\mathrm{CNO}$ face of the $\mathrm{W}(\mathrm{NH})\left(\mathrm{CH}_{2}\right)\left(\mathrm{OCH}_{3}\right)_{2}$ catalyst. 


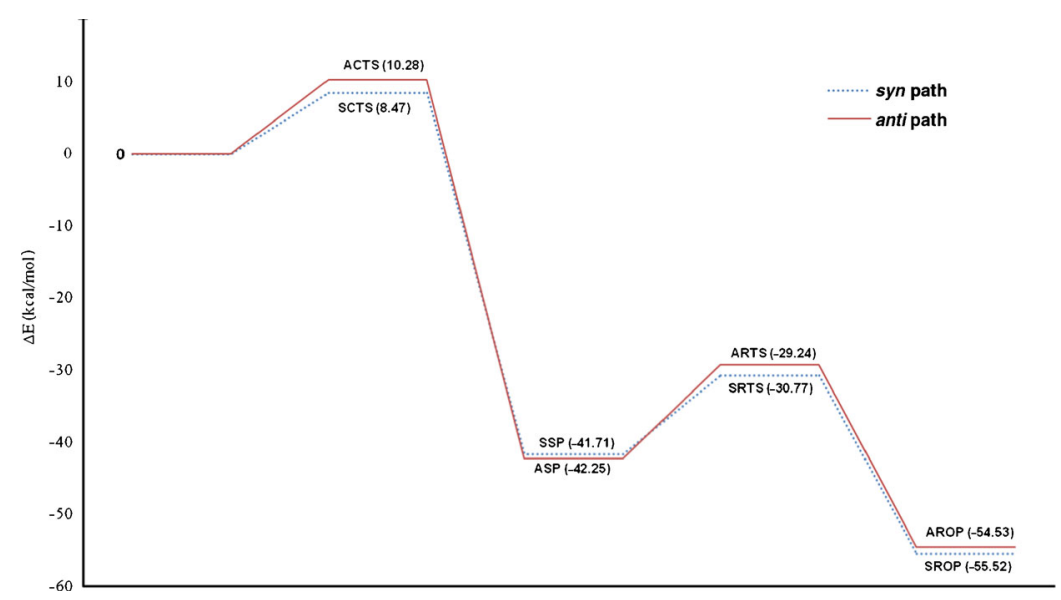

Figure 8. Energy diagram of the ring opening reaction of 3,3-dimethyl cyclopropene at the $\mathrm{CNO}$ face of the $\mathrm{W}(\mathrm{NH})\left(\mathrm{CH}_{2}\right)\left(\mathrm{OCH}_{3}\right)_{2}$ catalyst. The relative energies $\Delta \mathrm{E}(\mathrm{kcal} / \mathrm{mol})$ are obtained relative to the energy of the reactants.

opening step, with molybdenum catalyst shows that the cyclopropene metathesis proceeds much more easily as compared to tungsten catalyst.

3.2b Ring opening products: The optimized structures of the syn and anti alkylidenes formed by ring opening of the tungstacyclobutane intermediates are shown in figure 7 . These syn and anti ring opening products (new alkylidenes) are named as SROP and AROP, respectively. In both SROP and AROP two new bonds $\mathrm{W} 1=\mathrm{C} 6$ and $\mathrm{C} 1=\mathrm{C} 4$ have been formed with length of 1.91 and $1.35 \AA$, respectively, while $\mathrm{W} 1=\mathrm{C} 1$ and $\mathrm{C} 4=\mathrm{C} 6$ bonds have entirely broken (see entry $2-5$, table 2). The basic structures of these ring opening products are in agreement with previous experimental results on similar metal alkylidenes. ${ }^{48}$

The enthalpies of the new formed alkylidene (SROP and AROP) demonstrate that the ring opening of the cyclopropene moiety is an exothermic process whether the reaction proceeds through syn or anti orientations. The calculated enthalpies for syn and anti products are -52.02 and $-50.72 \mathrm{kcal} / \mathrm{mol}$, respectively. The syn product is stabler than the anti product by $1.30 \mathrm{kcal} / \mathrm{mol}$. The calculated free energy also favoured the syn path (see table 1). The overall kinetic profile of the ring opening metathesis reactions of cyclopropene at the $\mathrm{CNO}$ face of the catalyst $\mathrm{W}(\mathrm{NH})\left(\mathrm{CH}_{2}\right)\left(\mathrm{OCH}_{3}\right)_{2}$ is illustrated in figure 8 . For the cycloaddition intermediates, the most stable structures of the tungstacyclobutane are used.

The ring opened products SROP and AROP of the CNO face may act as a metal alkylidene $\mathrm{W}(\mathrm{NH})(\mathrm{CHR})\left(-\mathrm{OCH}_{3}\right)_{2}$ (where $\mathrm{R}=$ propagating chain) for the propagation step of the reaction. The 3,3-dimethyl cyclopropene may react in syn and anti manner with both alkylidene to yield the actual products of the metathesis reaction. Depending on the cyclopropene approach to the propagating alkylidene (SROP or AROP) stereochemically cis or trans macromolecules may formed as actual products of metathesis reaction.

\section{Conclusion}

In the present work, the ring opening by metathesis of highly strained 3,3-dimethyl cyclopropene with tungsten catalyst of the type $\mathrm{W}(\mathrm{NH})\left(\mathrm{CH}_{2}\right)\left(\mathrm{OCH}_{3}\right)_{2}$ has been studied. The reaction proceeds through two distorted trigonal bipyramidal transition structures. The transition structures of ring opening step are more twisted than those for the cycloaddition step. There is a significant preference for addition of cyclopropene to the CNO face of the catalyst over the COO face. Since the barrier for the cycloaddition step is lower than that for the ring opening step, we predict that the ring opening step is the rate determining step for the ROM of cyclopropene with the tungsten catalyst, in contrast with the earlier findings with molybdenum catalyst. The approach of cyclopropene to the $\mathrm{W}(\mathrm{NH})\left(\mathrm{CH}_{2}\right)\left(\mathrm{OCH}_{3}\right)_{2}$ with syn orientation is favourable for the ring opening and the resulting syn product is more stable than the anti product by $1.3 \mathrm{kcal} / \mathrm{mol}$. However, the differences in the stability of syn and anti products is not very high and kinetically the syn path is preferred over the anti path of ring opening metathesis of highly strained cyclopropene with tungsten catalyst.

It is well-known that steric effects are important to the reactivity of these syn and anti alkylidene catalysts 
as well as to the stability of the tungstacyclobutane intermediates and the stereochemistry of the out coming polymers. Further investigations of ROMP of cyclopropene derivatives with other transition metal alkylidenes are in progress.

\section{Supplementary information}

The selected optimized geometrical parameters of the reactants (model catalyst $\mathrm{W}(\mathrm{NH})\left(\mathrm{CH}_{2}\right)\left(\mathrm{OCH}_{3}\right)_{2}$ and 3,3-dimethyl cyclopropene are given in table $\mathrm{S} 1$ and for species involved in the reaction path are in table S2. The optimized Cartesian coordinates with total electronic energy (in hartree) of all structures are given in table S3. Supplementary tables S1-S3 can be seen in www.ias.ac.in/chemsci.

\section{Acknowledgement}

JSM is thankful to the Ministry of Human Resources and Development (MHRD), Government of India, for the award of Fellowship.

\section{References}

1. Burtscher D and Grela K 2009 Angew. Chem. Int. Ed. 48 442

2. Samec J S M and Grubbs R H 2008 Chem. Eur. J. 14 2686

3. Hoveyda A H and Zhugralin A R 2007 Nature 450 243

4. Grubbs R H 2006 Angew. Chem. Int. Ed. 453760

5. Schrock R R 2006 Angew. Chem. Int. Ed. 453748

6. Feldman J, Davis W M and Schrock R R 1989 Organometallics 82266

7. Schrock R R, Murdzek J S, Bazan G C, Robbins J, DiMare M and O'Regan M $1990 \mathrm{~J}$. Am. Chem. Soc. 1123875

8. Nguyen S T, Johnson L K, Grubbs R H and Ziller J W 1992 J. Am. Chem. Soc. 1143974

9. Anderson-Wile A M, Coates G W, Auriemma F, Rosa C D and Silvestre A 2012 Macromolecules 45 7863

10. Schrock R R 2011 Dalton Trans. 407484

11. Yu M, Ibrahem I, Hasegawa M, Schrock R R and Hoveyda A H 2012 J. Am. Chem. Soc. 1342788

12. Zuercher W J, Hashimoto M and Grubbs R H $1996 \mathrm{~J}$. Am. Chem. Soc. 1186634

13. Herrisson J L and Chauvin Y 1971 Makromol. Chem. 141161

14. Haigh D M, Kenwright A M and Khosravi E 2004 Tetrahedron 607217

15. Bazan G C, Oskam J H, Cho H N, Park L Y and Schrock R R 1991 J. Am. Chem. Soc. 1136899

16. Grela K 2008 Angew. Chem. Int. Ed. 475504

17. Flook M M, Gerber L C H, Debelouchina G T and Schrock R R 2010 Macromolecules $\mathbf{4 3} 7515$
18. Charvet R and Novak B M 2001 Macromolecules 34 7680

19. Grubbs R H 2003 Handbook of metathesis 1st edn. (New York:Wiley-VCH) Vol.1

20. Khoury P R, Goddard J D and Tam W 2004 Tetrahedron 608103

21. Singh R, Czekelius C and Schrock R R 2006 Macromolecules 391316

22. Binder W H, Pulamagatta B, Kir O, Kurzhals S, Barqawi H and Tanner S 2009 Macromolecules 42 9457

23. Tia R and Adei E 2011 Comput. Theor. Chem. 9718

24. Suresh C H and Koga N 2004 Organometallics 2376

25. Fomine S, Vargas S M and Tlenkopatchev M A 2003 Organometallics 2293

26. Fomine S, Ortega J V and Tlenkopatchev M A 2006 J. Organomet. Chem. 6913343

27. Fomine S and Tlenkopatchev M A 2007 Organometallics $\mathbf{2 6} 4491$

28. Martinez H, Miró P, Charbonneau P, Hillmyer M A and Cramer C J 2012 ACS Catal. 22547

29. Song A, Lee J C, Parker K A and Sampson N S 2010 J. Am. Chem. Soc. 13210513

30. Wu Y D and Peng Z H 2003 Inorg. Chim. Acta. 345241

31. Meena J S and Thankachan P P 2013 Comp. Theor. Chem. 10241

32. Frisch M J, Trucks G W, Schlegel H B, Scuseria G E, Robb M A, Cheeseman J R, Scalmani G, Barone V, Mennucci B, Petersson G A, Nakatsuji H, Caricato M, Li X, Hratchian H P, Izmaylov A F, Bloino J, Zheng G, Sonnenberg J L, Hada M, Ehara M, Toyota K, Fukuda R, Hasegawa J, Ishida M, Nakajima T, Honda Y, Kitao O, Nakai H, Vreven T, Montgomery Jr. J A, Peralta J E, Ogliaro F, Bearpark M, Heyd J J, Brothers E, Kudin K N, Staroverov V N, Kobayashi R, Normand J, Raghavachari K, Rendell A, Burant J C, Iyengar S S, Tomasi J, Cossi M, Rega N, Millam J M, Klene M, Knox J E, Cross J B, Bakken V, Adamo C, Jaramillo J, Gomperts R, Stratmann R E, Yazyev O, Austin A J, Cammi R, Pomelli C, Ochterski J W, Martin R L, Morokuma K, Zakrzewski V G, Voth G A, Salvador P, Dannenberg J J, Dapprich S, Daniels A D, Farkas Ö, Foresman J B, Ortiz J V, Cioslowski J and Fox D J 2009 Gaussian09, Revision A.02, Gaussian, Inc., Wallingford CT

33. Becke A D 1993 J. Chem. Phys. 985648

34. Lee C T, Yang W T and Parr R G 1988 Phys. Rev. B 37 785

35. Hay P J and Wadt W R 1985 J. Chem. Phys. 82299

36. Guan J, Yang G, Zhou D, Zhang W, Liu X and Bao X H X 2008 Catal. Commun. 92213

37. Handzlik J 2003 J. Catal. 22023

38. Tlenkopatchev M and Fomine S 2001 J. Organomet. Chem. 630157

39. Gonzalez C and Schlegel H B 1989 J. Chem. Phys. 90 2154

40. Gonzalez C and Schlegel H B 1990 J. Phys. Chem. 94 5523

41. Feldman J, Davis W M, Thomas J K and Schrock R R 1990 Organometallics 92535

42. Bazan G C, Khosravi E, Schrock R R, Feast W J, Gibson V C, O'Regan M B, Thomas J K and Davis W M 1990 J. Am. Chem. Soc. 1128378 
43. Oskam J H and Schrock R R 1993 J. Am. Chem. Soc. 11511831

44. Wu Y D and Peng Z H 1997 J. Am. Chem. Soc. 1198043

45. Folga E and Ziegler T 1993 Organometallics 12325

46. Handzlik J and Ogonowski J 2002 J. Mol. Catal. A: Chem. 184371
47. Schrock R R and Hoveyda A H 2003 Angew. Chem. Int. Ed. 424592

48. Schrock R R, DePue R T, Feldman J, Yap K B, Yang D C, Davis W M, Park L, DiMare M, Schofield M, Anhaus J, Walborsky E, Evitt E, Kruger C and Betz P 1990 Organometallics 92262 